\title{
Role of SLV in SLI substrate recognition by the Neurospora VS ribozyme
}

\author{
PATRICIA BOUCHARD, ${ }^{1,4}$ JULIE LACROIX-LABONTÉ, ${ }^{1,4}$ GENEVIÈVE DESJARDINS, ${ }^{1}$ PHILIPE LAMPRON, ${ }^{1}$ \\ VÉRONIQUE LISI, ${ }^{3}$ SÉBASTIEN LEMIEUX, ${ }^{2,3}$ FRANÇOIS MAJOR, $^{2,3}$ and PASCALE LEGAULT ${ }^{1}$ \\ ${ }^{1}$ Département de Biochimie, Université de Montréal, Montréal, H3C 3J7 Canada \\ ${ }^{2}$ Département d'Informatique et de Recherche Opérationnelle, Université de Montréal, Montréal, H3C 3J7 Canada \\ ${ }^{3}$ Institut de Recherche en Immunologie et en Cancérologie, Université de Montréal, Montréal, H3C 3J7 Canada
}

\begin{abstract}
Substrate recognition by the VS ribozyme involves a magnesium-dependent loop/loop interaction between the SLI substrate and the SLV hairpin from the catalytic domain. Recent NMR studies of SLV demonstrated that magnesium ions stabilize a U-turn loop structure and trigger a conformational change for the extruded loop residue U700, suggesting a role for U700 in SLI recognition. Here, we kinetically characterized VS ribozyme mutants to evaluate the contribution of U700 and other SLV loop residues to SLI recognition. To help interpret the kinetic data, we structurally characterized the SLV mutants by NMR spectroscopy and generated a three-dimensional model of the SLI/SLV complex by homology modeling with MC-Sym. We demonstrated that the mutation of U700 by A, C, or G does not significantly affect ribozyme activity, whereas deletion of U700 dramatically impairs this activity. The U700 backbone is likely important for SLI recognition, but does not appear to be required for either the structural integrity of the SLV loop or for direct interactions with SLI. Thus, deletion of U700 may affect other aspects of SLI recognition, such as magnesium ion binding and SLV loop dynamics. As part of our NMR studies, we developed a convenient assay based on detection of unusual ${ }^{31} \mathrm{P}$ and ${ }^{15} \mathrm{~N} \mathrm{N7}$ chemical shifts to probe the formation of U-turn structures in RNAs. Our model of the SLI/SLV complex, which is compatible with biochemical data, leads us to propose novel interactions at the loop I/loop V interface.
\end{abstract}

Keywords: Neurospora VS ribozyme; substrate recognition; loop/loop interaction; NMR structural probing; kinetic studies; RNA homology modeling

\section{INTRODUCTION}

RNA hairpins play many essential roles as basic elements of RNA structure. They guide the folding of RNA, help maintain its structural integrity, and serve as recognition motifs in RNA-RNA and RNA-protein interactions. RNA hairpins have recently gained increasing interest given the central role played by microRNAs and various other noncoding RNAs in the regulation of gene expression (Fire et al. 1998; Svoboda and Di Cara 2006). Therefore, it is important to understand how these small RNA building blocks assemble to form complex RNA-based architectures and support important biological functions.

\footnotetext{
${ }^{4}$ These authors contributed equally to this work.

Reprint requests to: Pascale Legault, Département de Biochimie, Université de Montréal, C.P. 6128, Succursale Centre-Ville, Montréal QC, H3C 3J7 Canada; e-mail: pascale.legault@umontreal.ca; fax: (514) 343-2210.

Article published online ahead of print. Article and publication date are at http://www.rnajournal.org/cgi/doi/10.1261/rna.824308.
}

Small ribozymes, such as the hammerhead, hairpin, HDV, and VS ribozymes, represent simple RNA architectures capable of enzymatic activity, and have been widely used as model systems to understand structure-function relationships in RNA. The VS ribozyme is one of these few naturally occurring ribozymes, which possesses a unique tertiary structure to perform its functions and has the distinct ability to recognize a hairpin substrate through formation of a loop/loop tertiary interaction (for recent reviews, see Collins 2002; Lilley 2004). Its catalytic activities are metal-dependent phosphodiester bond cleavage and ligation reactions, which both involve $5^{\prime}-\mathrm{OH}$ and $2^{\prime}, 3^{\prime}-$ cyclic phosphate termini (Saville and Collins 1990, 1991). Although the natural VS ribozyme isolated from the mitochondria of certain strains of Neurospora performs self-cleavage activity (Saville and Collins 1990), VS ribozyme fragments of $\sim 100-160$ nucleotides (nt) can perform cleavage in trans when incubated with small hairpin substrates in vitro (Guo and Collins 1995). 
There is currently no high-resolution structure of the VS ribozyme, but structural information is available from the proposed secondary structure (Fig. 1A; Beattie et al. 1995), tertiary structure models (Hiley and Collins 2001; Lafontaine et al. 2002), and NMR structures of individual stem-loops (Michiels et al. 2000; Flinders and Dieckmann 2001, 2004; Hoffmann et al. 2003; Campbell and Legault 2005; Campbell et al. 2006). The catalytic domain of the VS ribozyme consists of five stem-loop subdomains (SLII-SLVI) (Fig. 1A), and stem-loop I (SLI) (Fig. 1B) defines the substrate domain (Beattie et al. 1995). The cleavage site is located within the internal loop of stem-loop I, between nucleotides G620 and A621 (Saville and Collins 1990). Our present understanding is that in order for cleavage to occur, the cleavage site internal loop must dock in a cleft formed by SLII and SLVI to allow its interaction with the active site formed by the A730 loop of SLVI (Sood et al. 1998;

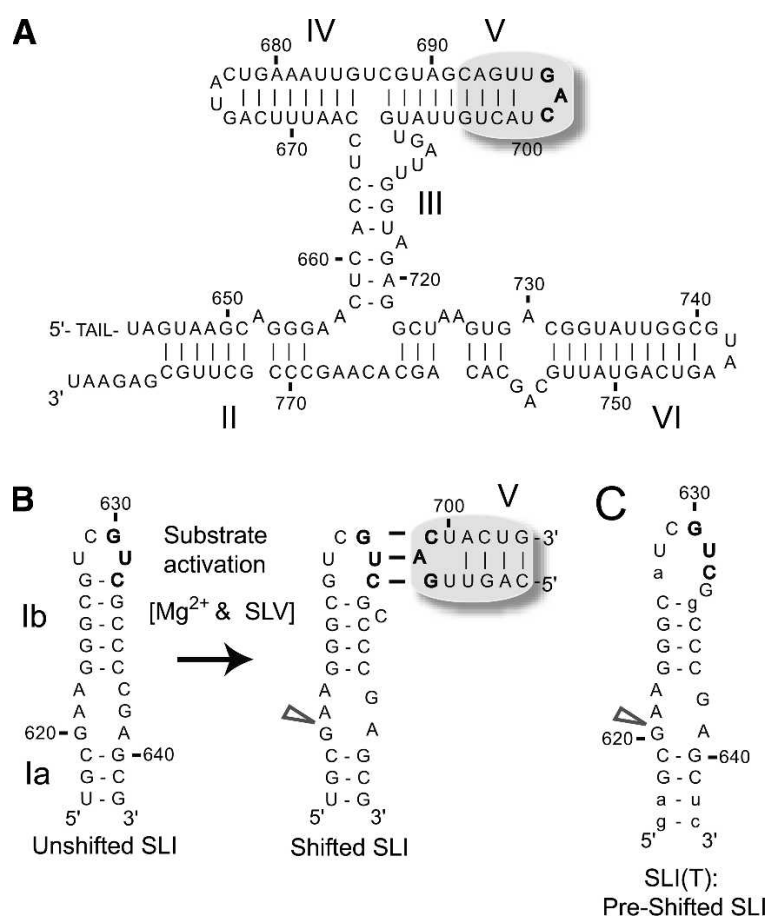

FIGURE 1. Substrate recognition by the Neurospora VS ribozyme. (A) Primary and secondary structures of the catalytic domain of the VS ribozyme. For this study, the Aval ribozyme was used; it includes a $5^{\prime}$-TAIL with the sequence: $5^{\prime}$-gggaaagcuGCGG-3' (Guo and Collins 1995). (B) The catalytic domain recognizes the SLI substrate (subdivided in Ia and $\mathrm{Ib}$ ) via a loop/loop interaction involving residues 630-632 of SLI and residues 697-699 of SLV. Upon interaction with SLV, the SLI RNA with the wild-type sequence undergoes a structural change from an unshifted to a shifted conformation; only the later allows cleavage of the SLI internal loop at the site indicated by an arrowhead. (C) Preshifted mutant substrates, such as SLI(T), are efficiently cleaved by the VS catalytic domain (Andersen and Collins 2000; Zamel and Collins 2002). Wild-type and mutant nucleotides are represented by upper- and lowercase, respectively. Specific SLI and SLV nucleotides are color coded for easy identification in subsequent figures.
Lafontaine et al. 2001; Collins 2002; Lilley 2004). The proposed catalytic mechanism for site-specific cleavage relies on the direct participation of G638 from the internal loop of SLI and A756 from the A730 loop of SLVI in general acid-base catalysis (Wilson et al. 2007).

Substrate recognition by the VS ribozyme involves a loop/loop interaction between SLI and SLV, which is stabilized by magnesium ions $\left(\mathrm{Mg}^{2+}\right)$. Mutational studies have provided evidence for three Watson-Crick base pairs involving nucleotides 630-632 of loop I and nucleotides 697-699 of loop V (Rastogi et al. 1996). Formation of this tertiary interaction is accompanied by a rearrangement of SLI from an unshifted to a shifted conformation (Fig. 1B), which affects the structure of the cleavage site internal loop (Andersen and Collins 2000, 2001). SLI mutants that cannot adopt the shifted conformation are not cleaved by the VS ribozyme, whereas those that can adopt the shifted conformation are active in the cleavage reaction (Fig. 1B,C) (Andersen and Collins 2000). Three-dimensional structures of small hairpins containing the unshifted (inactive) and shifted (active) internal loop conformations have been determined by NMR spectroscopy (Michiels et al. 2000; Flinders and Dieckmann 2001; Hoffmann et al. 2003). It appears from these structures that the active conformation contains a unique $\mathrm{Mg}^{2+}$-binding site and a unique tertiary interaction motif, both of which may be important for catalysis (Hoffmann et al. 2003).

To better understand the role of the SLV receptor in SLI recognition, we have determined two NMR structures for an SLV fragment (Fig. 2), one in the absence (SLV free) (Campbell and Legault 2005) and one in the presence of magnesium ions (SLV ${ }^{\mathrm{Mg}}$ ) (Campbell et al. 2006). The loop of $\mathrm{SLV}^{\text {free }}$ forms a loose noncanonical U-turn motif, whereas that of SLV ${ }^{\mathrm{Mg}}$ forms a compact canonical U-turn motif (Campbell and Legault 2005; Campbell et al. 2006). The U-turn of SLV ${ }^{\text {free }}$ was termed noncanonical, because it lacks the stacking interaction between the U696 base and the A698 5' -phosphate and the hydrogen bond between the U696 H3 and the A698 3'-phosphate (Fig. 2) that are characteristic of canonical U-turn structures and found in SLV $^{\mathrm{Mg}}$ (Campbell and Legault 2005; Campbell et al. 2006). Although $\mathrm{Mg}^{2+}$ ions affect the loop conformation, they do not significantly change the conformation of the three SLV bases (G697, A698, and C699) that are proposed to base pair with SLI (Rastogi et al. 1996). In both structures, these three bases of SLV are exposed and well positioned for binding to SLI (Campbell and Legault 2005; Campbell et al. 2006). The most significant change induced by $\mathrm{Mg}^{2+}$ ions occurs at the extruded loop residue U700, which comes closer to the three interacting bases (G697, A698, and C699) of SLV (Fig. 2) (Campbell et al. 2006). Given this $\mathrm{Mg}^{2+}$-dependent conformational change of U700 and the fact that $\mathrm{Mg}^{2+}$ ions stabilize the loop I/loop $\mathrm{V}$ interaction, we hypothesized that U700 could play an important role in SLI recognition (Campbell et al. 2006). 


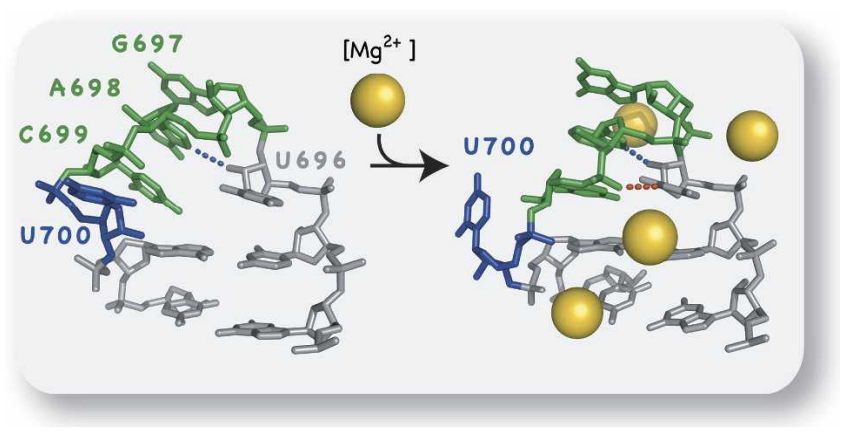

FIGURE 2. NMR structures of the SLV loop determined in the absence (left) and presence (right) of magnesium ions (Campbell and Legault 2005; Campbell et al. 2006), showing the large conformational change of U700 (blue). The dotted lines represent two hydrogen bonds that are characteristic of canonical U-turn structures, the A698 N7 to U696 2'OH (blue) and the U696 H3 to A698 3'-phosphate interactions (red). For simplicity, only heavy atoms are shown.

In the present study, we explored the role of U700 and other SLV features (loop-closing base pair, nucleotide insertion) in SLI recognition. We first performed kinetic experiments with the VS ribozyme containing mutations in loop V to better understand the SLV loop requirements for catalysis. To analyze the effects of these mutations on the structural integrity of the U-turn structure in the SLV loop, we developed an NMR-based assay to allow quick structural mapping of small SLV fragments. Given that the structure of SLV ${ }^{\mathrm{Mg}}$ is available and that structural characteristics of the SLI loop have been previously derived from biochemical data, we used homology modeling to obtain a structural model of the SLI/SLV interaction. This model helps explain our kinetic results and allows us to propose novel interactions at the loop $\mathrm{I} /$ loop $\mathrm{V}$ interface.

\section{RESULTS}

\section{Using $\mathrm{k}_{\mathrm{cat}} / \mathrm{K}_{M}$ values to investigate $\mathrm{SLI}$ recognition}

To better understand the role of U700 and other SLV loop features in substrate recognition, we initiated kinetic studies of trans cleavage with the VS ribozyme (Guo and Collins 1995). We used the previously characterized AvaI VS ribozyme (Rz) (Guo and Collins 1995), either the wildtype RNA (Fig. 1A) or RNAs containing a variety of mutations in the SLV loop (Fig. 3). Binding of this ribozyme to the wild-type SLI substrate involves the loop $\mathrm{I} /$ loop $\mathrm{V}$ interaction and a conformational change from the unshifted state to the shifted state, which activates the substrate for catalysis (Fig. 1B). The SLI(T) substrate (S) was selected for kinetic studies, because it can only adopt a preshifted active state (Fig. 1C; Andersen and Collins 2000; Zamel and Collins 2002).

The second-order rate constant $\left(\mathrm{k}_{\mathrm{cat}} / \mathrm{K}_{\mathrm{M}}\right)$ for the reaction of $\mathrm{Rz}$ with $\mathrm{S}$ was determined in single-turnover experiments (Herschlag and Cech 1990), as illustrated for the U700G mutant $\mathrm{Rz}$ in Figure 4. Cleavage experiments were performed with ${ }^{32} \mathrm{P}$-labeled $\mathrm{S}$ and excess $\mathrm{Rz}$, and the conversion of substrate into product was monitored by gel electrophoresis (Fig. 4A). For these experiments, the natural $\log$ of the fraction of remaining substrate was plotted against the time of the reaction, and the value of the first-order rate constant, $\mathrm{k}_{\mathrm{obs}}$, was derived from the slope of the graph, as shown in Figure 4B. For the wild-type and mutant Rz, a linear relationship was observed when $\mathrm{k}_{\mathrm{obs}}$ was plotted as a function of $\mathrm{Rz}$ concentration, and the values of catalytic efficiency $\left(\mathrm{k}_{\mathrm{cat}} / \mathrm{K}_{\mathrm{M}}\right)$ were obtained from the slope of that graph (Fig. 4C). Table 1 provides a summary of the $\mathrm{k}_{\mathrm{cat}} / \mathrm{K}_{\mathrm{M}}$ values and of the relative catalytic efficiencies of the wild-type (WT) and mutant (MUT) ribozymes $\left[\left(\mathrm{k}_{\mathrm{cat}} / \mathrm{K}_{\mathrm{M}}\right)_{\mathrm{WT}} /\left(\mathrm{k}_{\mathrm{cat}} / \mathrm{K}_{\mathrm{M}}\right)_{\mathrm{MUT}}\right]$.

The parameter $\mathrm{k}_{\mathrm{cat}} / \mathrm{K}_{\mathrm{M}}$ is an important kinetic constant that combines both the rate and the binding terms, and values of $k_{\text {cat }} / \mathrm{K}_{\mathrm{M}}$ of wild-type and mutant enzymes can be compared to address the role of specific residues in catalysis. For enzymes mutated at residues involved only in substrate binding and not in the reaction chemistry, $\mathrm{k}_{\mathrm{cat}} / \mathrm{K}_{\mathrm{M}}$ values of wild-type and mutant enzymes have been used to analyze the contribution of the mutated residues to the stabilization of the enzyme-substrate complex (Wilkinson et al. 1983; Fersht et al. 1985).

Biochemical studies have implicated residues from the SLV loop in SLI substrate recognition (Rastogi et al. 1996), and there is no evidence that SLV residues participate in the reaction chemistry (Wilson et al. 2007). Therefore, $\mathrm{k}_{\mathrm{cat}} /$ $\mathrm{K}_{\mathrm{M}}$ values measured for VS ribozymes carrying mutations in the SLV loop can be used to analyze the contribution of

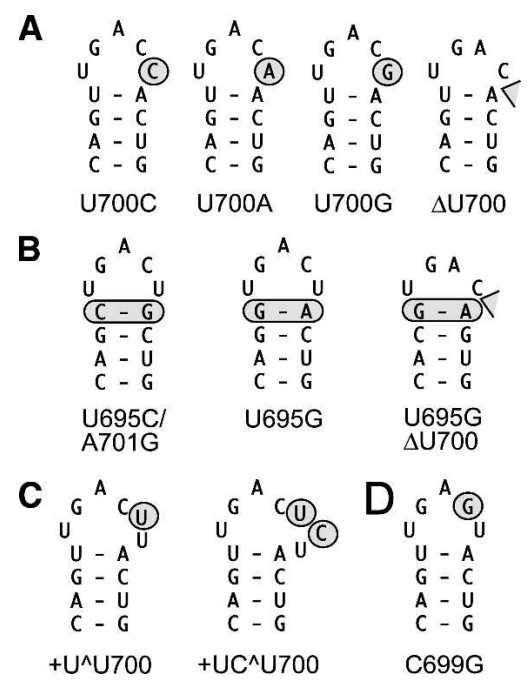

FIGURE 3. SLV loop mutants characterized kinetically and structurally in this study. Sequence and secondary structure of (A) SLV with U700 mutations and deletion, (B) SLV with mutations of the loopclosing base pair, (C) SLV with insertions of nucleotides between residues $\mathrm{C} 699$ and $\mathrm{U} 700$, and $(D)$ SLV with a loop mutation that is expected to disrupt the loop I/loop V interaction (Rastogi et al. 1996) and also serves as an experimental control. 

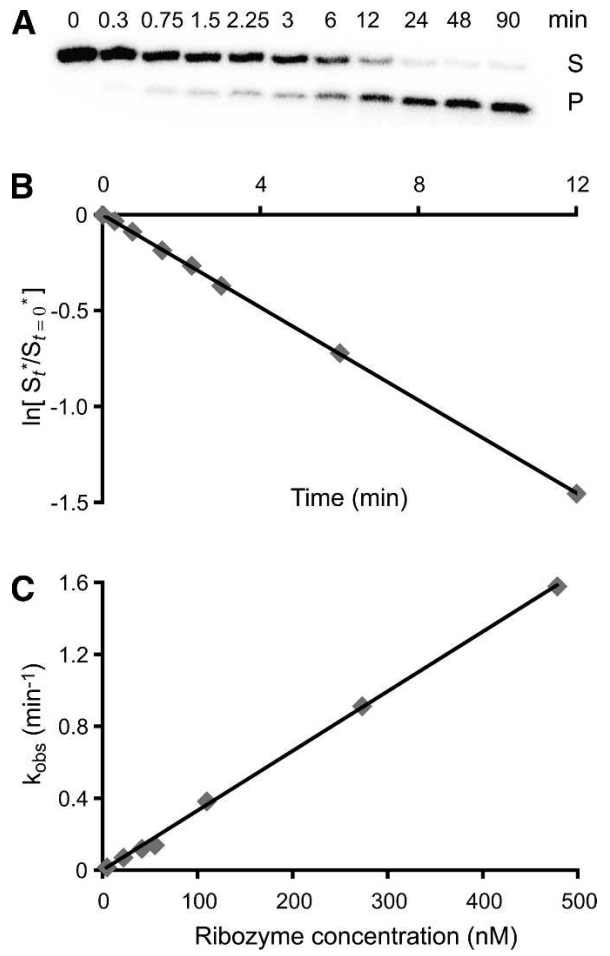

FIGURE 4. Kinetic analysis of the U700G Rz mutant. (A) Cleavage of ${ }^{32} \mathrm{P}$-labeled $\mathrm{SLI}(\mathrm{T})$ by the $\mathrm{U} 700 \mathrm{G} \mathrm{Rz}$ is performed at $30^{\circ} \mathrm{C}$ in the presence of $25 \mathrm{mM} \mathrm{MgCl} 2$ under single turnover conditions (excess enzyme $[37.5 \mathrm{nM}]$ over substrate $[0.25 \mathrm{nM}]$ ). Denaturing polyacrylamide gel electrophoresis shows the amount of substrate $(\mathrm{S})$ and product $(\mathrm{P})$ at various time points of the reaction. (B) The natural $\log$ of the fraction of remaining substrate is plotted against time (see Materials and Methods). The data are fit to a single exponential and the first order rate constant is extracted by linear regression $\left(\mathrm{k}_{\mathrm{obs}}=\right.$ absolute value of the slope $=0.12 \mathrm{~min}^{-1}$ and $\mathrm{R}^{2}=$ 0.9999). (C) Cleavage reactions with the U700G $\mathrm{Rz}$ are performed at various ribozyme concentrations and the value of $\mathrm{k}_{\mathrm{obs}}$ is plotted against ribozyme concentration. At low ribozyme concentration, there is a linear relationship between $\mathrm{k}_{\mathrm{obs}}$ and ribozyme concentration. The data are fit to a single exponential and the $\mathrm{k}_{\mathrm{cat}} / \mathrm{K}_{\mathrm{M}}$ is extracted by linear regression $\left(\mathrm{k}_{\text {cat }} / \mathrm{K}_{\mathrm{M}}=\right.$ value of the slope $=3.3 \mathrm{~min}^{-1} \mu \mathrm{M}^{-1}$ and $\left.\mathrm{R}^{2}=0.9988\right)$.

SLV loop residues to SLI recognition. SLI recognition is defined here as the binding of the SLI substrate to the transcleaving VS ribozyme and includes all ribozyme-substrate interactions.

Substrate recognition of the preshifted SLI(T) substrate used for our studies should involve formation of the loop I/ loop V interaction (Rastogi et al. 1996) and docking of SLI at the active site (Hiley et al. 2002; Lafontaine et al. 2002). Current data are consistent with the role of the SLV loop being limited to the loop I/loop V interaction (Rastogi et al. 1996), although it is possible that mutations of the SLV loop also affect the proper docking of SLI at the active site, either because this docking depends on SLV interaction(s) with the rest of the ribozyme or as a consequence of a perturbed loop I/loop $\mathrm{V}$ interface. In the context where an SLV mutation would disrupt proper SLI docking at the active site, both SLI binding and the rate of chemistry could be affected, and a quantitative analysis of the effect of the mutation on SLI binding would not be possible (Kraut et al. 2003). In addition, mutations in SLV could also affect the folding of the ribozyme and/or change the energy landscape of the reaction. Thus, the $\mathrm{k}_{\mathrm{cat}} / \mathrm{K}_{\mathrm{M}}$ values obtained here can only be interpreted in a qualitative manner; they provide information on the loop I/loop $\mathrm{V}$ interaction, but could also reflect other aspects of the ribozyme cleavage reaction.

\section{Kinetic properties of VS ribozymes carrying mutations in the SLV loop}

The values of $\mathrm{k}_{\mathrm{cat}} / \mathrm{K}_{\mathrm{M}}$ indicate that mutation of $\mathrm{U} 700$ by $\mathrm{A}$, $\mathrm{C}$, or $\mathrm{G}$ does not significantly disrupt ribozyme activity, since the ratios of $\left(\mathrm{k}_{\mathrm{cat}} / \mathrm{K}_{\mathrm{M}}\right)_{\mathrm{WT}} /\left(\mathrm{k}_{\mathrm{cat}} / \mathrm{K}_{\mathrm{M}}\right)_{\mathrm{MUT}}$ are less than 4 (Table 1). The U700G mutation is the least disruptive, followed by U700A and U700C. Deletion of U700, however, severely affects ribozyme activity, since the $\mathrm{k}_{\text {cat }} / \mathrm{K}_{\mathrm{M}}$ of the $\Delta \mathrm{U} 700$ mutant is reduced 140-fold compared with the wild-type value. The $\mathrm{k}_{\mathrm{cat}} / \mathrm{K}_{\mathrm{M}}$ value of $\Delta \mathrm{U} 700$ is similar to that of the positive control C699G $\left[\left(\mathrm{k}_{\mathrm{cat}} / \mathrm{K}_{\mathrm{M}}\right)_{\mathrm{WT}} /\right.$ $\left.\left(\mathrm{k}_{\mathrm{cat}} / \mathrm{K}_{\mathrm{M}}\right)_{\mathrm{MUT}}=270\right]$, a mutant that is expected to disrupt the formation of the loop I/loop V interaction (Rastogi et al. 1996).

Mutation of the loop-closing U695-A701 base pair by a C-G or a G-A base pair also does not significantly affect ribozyme activity, since $\left(\mathrm{k}_{\mathrm{cat}} / \mathrm{K}_{\mathrm{M}}\right)_{\mathrm{WT}} /\left(\mathrm{k}_{\mathrm{cat}} / \mathrm{K}_{\mathrm{M}}\right)_{\mathrm{MUT}}$ values of 4.1 and 2.7 are observed for the U695C/A701G and U695G mutants, respectively. However, deletion of U700 in the context of a loop-closing G-A base pair severely reduces ribozyme activity, since a $\left(\mathrm{k}_{\mathrm{cat}} / \mathrm{K}_{\mathrm{M}}\right)_{\mathrm{WT}} /\left(\mathrm{k}_{\mathrm{cat}} / \mathrm{K}_{\mathrm{M}}\right)_{\mathrm{MUT}}$ value of 74 was observed for the U695G/ $\Delta$ U700 mutant, a value similar to that of the $\Delta U 700$ mutant (Table 1), which contains the wild-type loop-closing U-A base pair.

Insertion of a single $U$ residue between C699 and U700 does not significantly affect ribozyme activity, since a $\left(\mathrm{k}_{\mathrm{cat}} /\right.$ $\left.\mathrm{K}_{\mathrm{M}}\right)_{\mathrm{WT}} /\left(\mathrm{k}_{\mathrm{cat}} / \mathrm{K}_{\mathrm{M}}\right)_{\mathrm{MUT}}$ value of 3.9 was observed for the

TABLE 1. Summary of kinetic data for the VS ribozyme mutants

\begin{tabular}{|c|c|c|}
\hline Ribozyme & $\begin{array}{c}\mathrm{k}_{\mathrm{cat}} / \mathrm{K}_{\mathrm{M}} \\
\left(\mathrm{min}^{-1} \mu \mathrm{M}^{-1}\right)\end{array}$ & $\frac{\left(\mathrm{k}_{\mathrm{cat}} / \mathrm{K}_{\mathrm{M}}\right)_{\mathrm{WT}}}{\left(\mathrm{k}_{\mathrm{cat}} / \mathrm{K}_{\mathrm{M}}\right)_{\mathrm{MUT}}}$ \\
\hline wild-type & $3.8 \pm 0.7$ & 1.0 \\
\hline U700C & $1.0 \pm 0.2$ & 3.7 \\
\hline U700A & $2.1 \pm 0.1$ & 1.8 \\
\hline U700G & $3.6 \pm 0.4$ & 1.0 \\
\hline$\Delta \cup 700$ & $0.028 \pm 0.004$ & $1.4 \times 10^{2}$ \\
\hline U695C/A701G & $0.9 \pm 0.1$ & 4.1 \\
\hline U695G & $1.4 \pm 0.3$ & 2.7 \\
\hline U695G/AU700 & $0.051 \pm 0.007$ & 74 \\
\hline$+U \wedge \cup 700$ & $0.98 \pm 0.09$ & 3.9 \\
\hline$+\cup C^{\wedge} \cup 700$ & $0.029 \pm 0.006$ & $1.3 \times 10^{2}$ \\
\hline C699G & $0.014 \pm 0.004$ & $2.7 \times 10^{2}$ \\
\hline
\end{tabular}


$+\mathrm{U} \wedge \mathrm{U} 700$ mutant. However, the insertion of the UC dinucleotide between C699 and U700 severely reduces ribozyme activity, as judged from the $\left(\mathrm{k}_{\mathrm{cat}} / \mathrm{K}_{\mathrm{M}}\right)_{\mathrm{WT}} /\left(\mathrm{k}_{\mathrm{cat}} / \mathrm{K}_{\mathrm{M}}\right)_{\mathrm{MUT}}$ value of 130 observed for the $+\mathrm{UC}^{\wedge} \mathrm{U} 700$ mutant.

\section{NMR studies of mutant SLV fragments}

To help interpret the kinetic data of the mutant ribozymes, we characterized SLV fragments containing the equivalent mutations (Fig. 3) by NMR spectroscopy. In order to ascertain that SLV fragments formed a hairpin as in the folded ribozyme and not a duplex conformation (Fig. 5A), they were analyzed by $1 \mathrm{D}$ imino ${ }^{1} \mathrm{H}$ NMR spectroscopy (data not shown) and native gel electrophoresis (Fig. 5B). The NMR data indicated that, except for U700A, wild-type SLV and all mutants adopted a single conformation in the absence of $\mathrm{Mg}^{2+}$. In the presence of $\mathrm{Mg}^{2+}$, the NMR data indicated the presence of a second conformation $(>10 \%)$ for select mutants. As illustrated in Figure 5B, the native gel data could be used to confirm that the hairpin conformation is favored for the majority of SLV mutants, but that a few mutants formed a mixed population of hairpin and duplex conformations. The presence of a significant population of duplex prevented further structural characterization of these mutants (Fig. 5B, U700A, U700G, $+\mathrm{UC} \wedge \mathrm{U} 700)$ by NMR. For the U700A and the U700G mutants, there is a clear possibility for base pairing involving residue 700 (A or G) and U696 (Fig. 5) that stabilizes the duplex conformation of the SLV fragment. It is important to note that the $\mathrm{k}_{\mathrm{cat}} / \mathrm{K}_{\mathrm{M}}$ values of the ribozyme mutants U700A and U700G are not significantly lower than
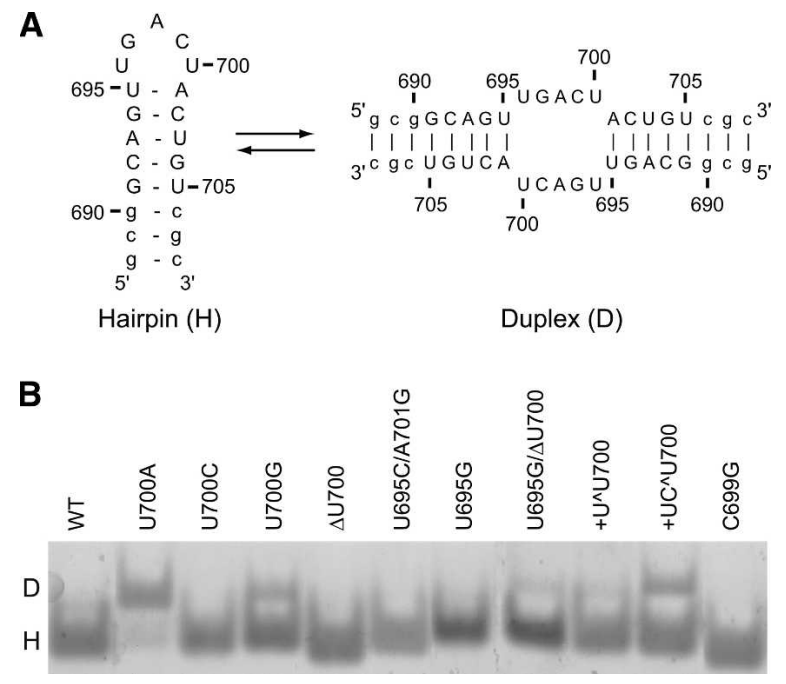

FIGURE 5. Conformation of SLV RNA fragments. (A) Primary and secondary structures of the wild-type SLV RNA fragment used for NMR studies in its hairpin (H) and duplex (D) conformations. (B) Native gel electrophoresis of the wild-type (WT) and mutant SLV RNAs. The RNAs were loaded at a concentration of $20 \mu \mathrm{M}$ in the presence of $20 \mathrm{mM} \mathrm{MgCl}_{2}$. that of the wild-type ribozyme (Table 1). Therefore, the observation that certain mutations produce duplexes with SLV fragments does not suggest that these same mutations produce misfolded and functionally impaired ribozymes. On the contrary, since all mutations were localized to the loop of SLV and hydroxyl radicals footprinting data indicate that SLV does not interact with other parts of the ribozyme in the absence of SLI (Hiley et al. 2002), it is likely that structural changes caused by our mutations would only affect the loop of SLV and not the general folding of the ribozyme. To obtain local structural information on the mutants, we compared their NMR data with that of the wild-type SLV.

Previous NMR studies of an SLV RNA fragment indicated that the SLV loop adopts a loose noncanonical U-turn fold in the absence of $\mathrm{Mg}^{2+}\left(\mathrm{SLV}^{\text {free }}\right)$, which becomes a compact canonical U-turn fold in the presence of $\mathrm{Mg}^{2+}\left(\mathrm{SLV}^{\mathrm{Mg}}\right.$ ) (Campbell and Legault 2005; Campbell et al. 2006). In agreement with previous NMR studies of U-turn structures (Schweisguth and Moore 1997; Sundaram et al. 2000; Cabello-Villegas et al. 2004), unusually large chemical shift changes were associated with the formation of a canonical U-turn structure in $\mathrm{SLV}^{\mathrm{Mg}}$ for two specific NMR signals, the ${ }^{31} \mathrm{P}$ resonance of U696 $3^{\prime}$-phosphate $\left(3^{\prime}-\mathrm{P}\right)$ and the ${ }^{15} \mathrm{~N}$ resonance of A698 N7 (Campbell and Legault 2005; Campbell et al. 2006). The detection of unusual ${ }^{31} \mathrm{P}$ and ${ }^{15} \mathrm{~N}$ chemical shifts in SLV RNA fragments was therefore used to identify the formation of a canonical U-turn fold for the mutants being functionally characterized in this study (Fig. 3).

NMR structural probing of the wild-type and mutant SLV RNAs involved the collection and analysis of $1 \mathrm{D}^{1} \mathrm{H}_{-}$ decoupled ${ }^{31} \mathrm{P}$ spectra and $2 \mathrm{D}{ }^{1} \mathrm{H}-{ }^{15} \mathrm{~N}$ long-range HMQC spectra (Kay and Bax 1990). In the $1 \mathrm{D}{ }^{31} \mathrm{P}$ spectra of the wild-type SLV RNA, distinct downfield-shifted signals were observed in the presence but not the absence of $\mathrm{Mg}^{2+}$ (Fig. 6A). Based on previous assignment, the ${ }^{31} \mathrm{P}$ signal of U696 $3^{\prime}-\mathrm{P}$ is the most downfield-shifted signal, $\sim 1.5 \mathrm{ppm}$ downfield from the main cluster of ${ }^{31} \mathrm{P}$ signals (Campbell et al. 2006). The unusual chemical shift of U696 3'-P was previously associated with formation of a canonical U-turn structure for $\mathrm{SLV}^{\mathrm{Mg}}$. In this structure, the 3'-P of U696 acts as the turning phosphate of the U-turn fold and is part of a negatively charged pocket that defines a $\mathrm{Mg}^{2+}$-binding site (Fig. 2; Campbell and Legault 2005; Campbell et al. 2006). The ${ }^{31}$ P NMR spectra of the C699G and $\Delta$ U700 mutants provide examples of data where a $\mathrm{Mg}^{2+}$-dependent ${ }^{31} \mathrm{P}$ downfield-shifted signal is either not observed (C699G) or less shifted from the main cluster of ${ }^{31} \mathrm{P}$ signals $(\Delta \mathrm{U} 700)$ when compared with the U696 3'-P resonance of the wildtype RNA (Fig. 6A). A summary of the ${ }^{31} \mathrm{P}$ chemical-shift data for the mutant RNAs is provided in Table 2. For all mutant RNAs, no significantly downfield-shifted signal was observed in the absence of $\mathrm{Mg}^{2+}$. In the presence of $\mathrm{Mg}^{2+}$, the extent of the ${ }^{31} \mathrm{P}$ downfield shift varied depending on 
A

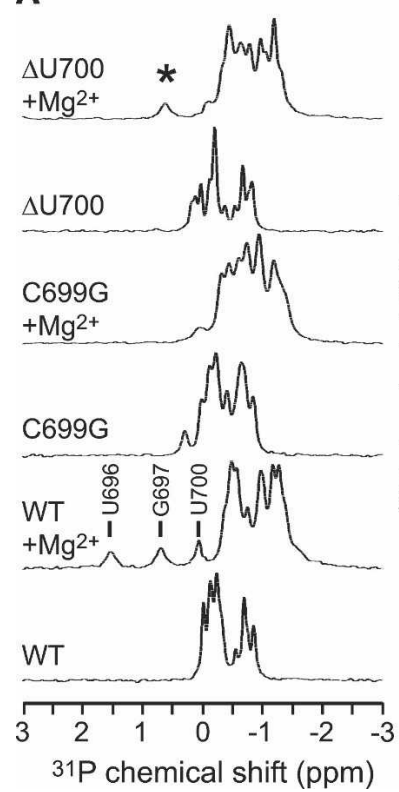

B

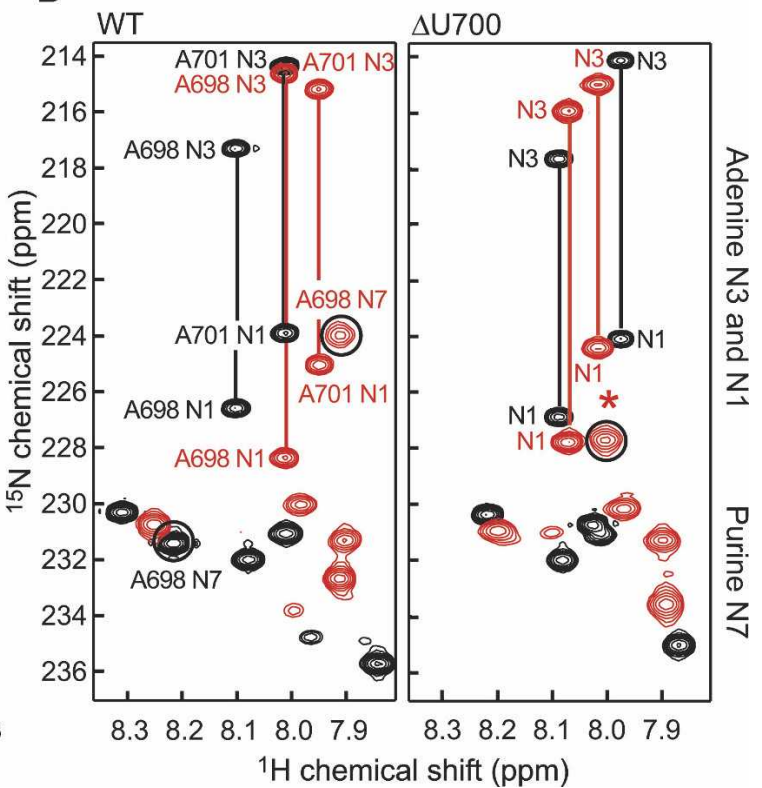

SLV (Fig. 6B). A summary of the 2D ${ }^{1} \mathrm{H}-{ }^{15} \mathrm{~N}$ long-range HMQC data for the mutant RNAs is provided in Table 2. For all mutants being studied, no significantly upfield-shifted N7 signal was observed in the absence of $\mathrm{Mg}^{2+}$. In the presence of $\mathrm{Mg}^{2+}$, upfield-shifted N7 resonances were observed for some mutant RNAs, and the results were separated in three classes based on their similarity with the chemical-shift value of A698 N7 (Table 2); they were typical of (Table 2, +: U695G and U695G/ $\Delta \mathrm{U} 700)$, not as significantly shifted as (Table 2, \pm : U700C, $\Delta$ U700, and U695C/A701G), or very different from (Table 2, -: +U^U700, C699G) values observed for the canonical U-turn structure of $\mathrm{SLV} \mathrm{Mg}^{\mathrm{Mg}}$.

It is interesting to note that in the presence of $\mathrm{Mg}^{2+}$, the extent of the N7 upfield shift (typical of [+], not as significantly shifted as $[ \pm]$, or very different from $[-]$ ) always matched the extent of the ${ }^{31} \mathrm{P}$ downfield shift for any given mutant (Table 2). The fact that these independent observations correlate with each other supports the use of these ${ }^{31} \mathrm{P}$ and ${ }^{15} \mathrm{~N}$ chemical shifts to examine the U-turn structure of SLV mutants. For the wild-type, U695G, and U695G/AU700 RNAs, their unusual ${ }^{31} \mathrm{P}$

the mutant RNA, and results were separated in three classes based on their similarity with the U696 3'-P chemical shift of the wild-type SLV (Table 2); they were typical of (Table 2, +: U695G and U695G/DU700), not as significantly shifted as (Table 2, \pm : U700C, $\Delta$ U700, and U695C/ A701G), or very different from (Table 2, $-:+\mathrm{U} \wedge \mathrm{U} 700$, C699G) values observed for the canonical U-turn structure of SLV $\mathrm{Mg}^{\mathrm{Mg}}$.

In the $2 \mathrm{D}^{1} \mathrm{H}_{-}{ }^{15} \mathrm{~N}$ long-range $\mathrm{HMQC}$ spectra of the wildtype SLV RNA, an upfield-shifted ${ }^{15} \mathrm{~N}$ resonance, assigned to the A698 N7-H8 cross-peak based on previous NMR studies (Campbell et al. 2006), was observed in the presence, but not the absence of $\mathrm{Mg}^{2+}$ (Fig. 6B). This unusual N7 chemical shift, $\sim 6 \mathrm{ppm}$ upfield from the main cluster of N7 signals, was previously attributed to the stabilization of the hydrogen bond between A698 N7 and U696 2'-OH within the canonical U-turn structure for SLV $^{\mathrm{Mg}}$ (Campbell and Legault 2005; Campbell et al. 2006). The $2 \mathrm{D}{ }^{1} \mathrm{H}-{ }^{15} \mathrm{~N}$ long-range HMQC spectra of the $\Delta \mathrm{U} 700$ mutant provide an example of data where a ${ }^{15} \mathrm{~N}$ upfieldshifted H8-N7 cross-peak is observed in $\mathrm{Mg}^{2+}$ only, but where the N7 chemical shift is not as shifted from the main cluster of N7 signals as the A698 N7 from the wild-type and ${ }^{15} \mathrm{~N}$ N7 chemical shifts indicate the formation of a canonical U-turn structure similar to that of $\mathrm{SLV}^{\mathrm{Mg}}$ (Fig. 2). For the $+\mathrm{U}^{\wedge} \mathrm{U} 700$ and C699G mutants, the absence of unusual ${ }^{31} \mathrm{P}$ and ${ }^{15} \mathrm{~N}$ N7 chemical shifts indicates that their loop does not form a canonical U-turn. In addition, the formation of a loose noncanonical U-turn fold in the $+\mathrm{U} \wedge \mathrm{U} 700$ and C699G mutant RNAs cannot be evaluated, because the loose noncanonical U-turn fold of SLV free did not yield unusual ${ }^{31} \mathrm{P}$ and ${ }^{15} \mathrm{~N}$ N7 chemical shifts (Campbell and Legault 2005). For the U700C, $\Delta$ U700, and U695C/A701G mutants, the extents of ${ }^{31} \mathrm{P}$ and ${ }^{15} \mathrm{~N}$ N7 shifts in the presence of $\mathrm{Mg}^{2+}$ were not as significant as for the wild-type RNA, indicating that their U-turn structure is more compact than for $\mathrm{SLV}^{\text {free }}$, but not as compact as for SLV $^{\mathrm{Mg}}$ (Fig. 2).

\section{Kinetic and NMR studies of mutants containing a G-A loop-closing base pair}

Hairpin loops containing U-turn structures are generally not closed by Watson-Crick base pairs as in SLV, but by noncanonical base pairs, such as the sheared G-A base pair. With the exception of SLV, the few U-turn structures with 
TABLE 2. Summary of NMR data for the SLV fragments

Values of selected chemical shifts (ppm)

\begin{tabular}{|c|c|c|c|c|c|c|}
\hline & & & & & & \\
\hline SLV fragment & $\mathrm{Mg}^{2+\mathrm{a}}$ & Hairpin $^{b}$ & & field shift ${ }^{c}$ & ${ }^{15} \mathrm{~N}$ & d shift ${ }^{\mathrm{c}}$ \\
\hline Wild type & - & Yes & - & -0.02 to -0.86 & - & 231.4 \\
\hline & + & Yes & + & 1.52 & + & 224.0 \\
\hline U700C & - & Yes & - & 0.09 to -0.83 & - & $>229.3$ \\
\hline & + & Yes & \pm & 0.76 & \pm & 227.4 \\
\hline U700A & - & No & n.d. & n.d. & n.d. & n.d. \\
\hline & + & No & n.d. & n.d. & n.d. & n.d. \\
\hline U700G & - & Yes & - & 0.38 to -0.87 & - & $>229.5$ \\
\hline & + & No & n.d. & n.d. & n.d. & n.d. \\
\hline$\Delta \cup 700$ & - & Yes & - & 0.17 to -0.83 & - & $>229.7$ \\
\hline & + & Yes & \pm & 0.61 & \pm & 227.7 \\
\hline U695C/A701G & - & Yes & - & -0.01 to -0.85 & - & $>230.7$ \\
\hline & + & Yes & \pm & 1.23 & \pm & 225.8 \\
\hline U695G & - & Yes & - & -0.03 to -0.83 & - & $>230.4$ \\
\hline & + & Yes & + & 1.51 & + & 225.1 \\
\hline U695G/AU700 & - & Yes & - & 0.32 to -0.85 & - & $>228.2$ \\
\hline & + & Yes & + & 1.49 & + & 224.1 \\
\hline$+U \wedge \cup 700$ & - & Yes & - & -0.03 to -0.86 & - & $>229.8$ \\
\hline & + & Yes & - & -0.42 to -1.21 & - & $>228.9$ \\
\hline$+\cup C^{\wedge} \cup 700$ & - & Yes & - & 0.00 to -0.85 & - & $>229.7$ \\
\hline & + & No & n.d. & n.d. & n.d. & n.d. \\
\hline C699G & - & Yes & - & 0.28 to -0.85 & - & $>229.2$ \\
\hline & + & Yes & - & 0.04 to -1.19 & - & $>229.1$ \\
\hline
\end{tabular}

n.d., Not determined.

${ }^{a}$ The buffer used was either NMR buffer A which does not contain $\mathrm{MgCl}_{2}(-)$ or $\mathrm{NMR}$ buffer $\mathrm{C}$, which contains $20 \mathrm{mM} \mathrm{MgCl} 2$ (+).

bThe conformation of the RNA was verified by native gels and NMR experiments.

${ }^{\mathrm{c} 31} \mathrm{P}$ downfield shifts and ${ }^{15} \mathrm{~N}$ N7 upfield shifts were typical of $(+)$, not as significantly shifted as $( \pm)$, or very different from $(-)$ values obtained for the canonical U-turn structure of SLV ${ }^{\mathrm{Mg}}$. Measured values are indicated. For ${ }^{31} \mathrm{P}$ data, the range of observed values is indicated when no distinct downfield signal was observed.

Watson-Crick loop-closing base pairs that have been structurally characterized form loose noncanonical U-turns (Campbell and Legault 2005). In Watson-Crick base pairs, the $\mathrm{C}^{\prime}-\mathrm{C} 1^{\prime}$ distance is larger than that of many noncanonical base pairs, and we previously suggested that this constrains the formation of a canonical U-turn fold (Campbell and Legault 2005). We hypothesized that replacing the Watson-Crick U-A base pair by a G-A base pair in SLV would remove this constraint and allow for formation of a compact canonical U-turn fold in the context of the $\Delta \mathrm{U} 700$ mutation. Consequently, if a canonical U-turn fold were sufficient for SLI recognition, this G-A mutant would allow SLI recognition, even following deletion of U700.

In agreement with our prediction, the NMR data clearly indicate that the U695G and U695G/DU700 mutants both adopt canonical U-turn structures in the presence of $\mathrm{Mg}^{2+}$ ions. In addition, mutation of the loop-closing U695-A701 base pair by a $\mathrm{G}-\mathrm{A}\left[\left(\mathrm{k}_{\mathrm{cat}} / \mathrm{K}_{\mathrm{M}}\right)_{\mathrm{WT}} /\left(\mathrm{k}_{\mathrm{cat}} / \mathrm{K}_{\mathrm{M}}\right)_{\mathrm{MUT}}=2.7\right]$ base pair has only a small effect on ribozyme activity. However, deletion of U700 in the context of a loop-closing G-A base pair has a damaging effect on ribozyme activity $\left[\left(\mathrm{k}_{\text {cat }} /\right.\right.$ $\left.\left.\mathrm{K}_{\mathrm{M}}\right)_{\mathrm{WT}} /\left(\mathrm{k}_{\mathrm{cat}} / \mathrm{K}_{\mathrm{M}}\right)_{\mathrm{MUT}}=74\right]$, similar to its effect in the wildtype context. It therefore appears that formation of a canonical structure in this $\Delta 700$ mutant is not sufficient to allow a favorable interaction with SLI.

\section{Homology modeling of the SLI/SLV interaction with MC-Sym}

A model of the SLI/SLV interaction was generated using the constraint-satisfaction program MC-Sym (Major et al. 1991; Major 2003). For these modeling studies, the previously determined NMR structure of $\mathrm{SLV}^{\mathrm{Mg}}$ was used (PDB entry 1YN1) (Campbell et al. 2006) as is, assuming that it would not be significantly changed by SLI binding. Although the structure of SLI with the wild-type terminal loop sequence has been previously determined by NMR (Flinders and Dieckmann 2001), these studies were performed in the absence of $\mathrm{Mg}^{2+}$ and/or SLV and, under those conditions, the SLI loop structure was not well defined by the NMR data (Flinders and Dieckmann 2001). Previous biochemical studies indicated that SLI adopts a U-turn structure important for its recognition by SLV and for efficient ribozyme activity (Rastogi et al. 1996; Sood et al. 2002; Jones and Strobel 2003). It is therefore likely that the loop of SLI adopts a U-turn structure when bound 
to SLV, and this SLI U-turn structure was constrained in our model of the SLI/SLV interaction. Previous mutational studies also indicated that SLI nucleotides G630, U631, and C632 form Watson-Crick base pairs with SLV nucleotides C699, A698, and G697, respectively (Rastogi et al. 1996). It is therefore likely that these three Watson-Crick base pairs stack on each other to adopt a short right-handed helix, and these three Watson-Crick base pairs between SLI and SLV were also constrained in our model.

The model shown in Figure 7 is a good representative of the seven models generated with MC-Sym and energy minimized with X-PLOR-NIH (heavy atom RMSD between 2.4 and $3.1 \AA$ ). This model indicates that the U-turn conformations of the SLI and SLV loops are compatible with formation of the three-predicted WatsonCrick base pairs at the loop/loop junction, at least from a geometrical standpoint. In all models obtained, the point of closest approach between the phosphodiester backbones of the two loops is at the turning phosphate of their respective U-turn structure (3'-P of U628 and U696). The

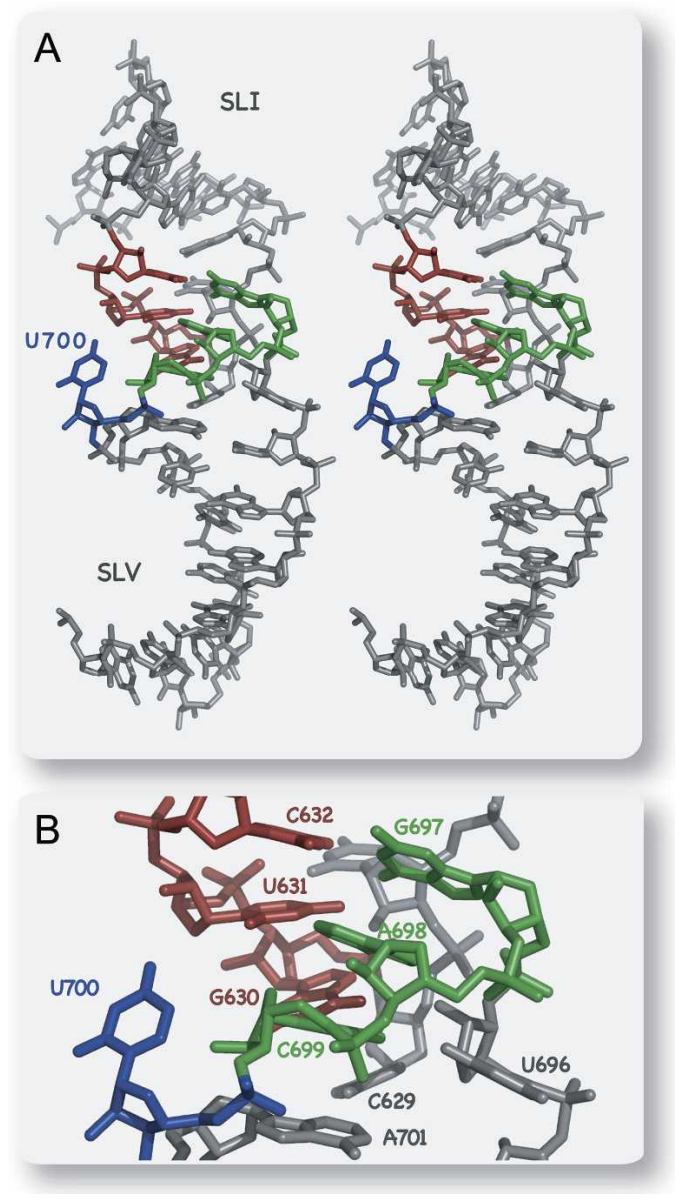

FIGURE 7. (A) Stereo view of a structural model of the SLI/SLV complex. The selected model is a representative of the seven structures obtained from homology modeling with MC-Sym. For simplicity, only heavy atoms are shown. $(B)$ Close up of the model shown in $A$.
U700 nucleotide is the SLV loop residue located the farthest from SLI; it is generally not positioned to form a stable interaction with SLI, although a few models suggest the possibility for a hydrogen-bonding interaction between the U700 O4 and the U631 2'-OH (Fig. 7). Interestingly, the models display interactions not previously identified: the stacking of C629 on G630 and a hydrogen bond between C629 NH2 and A701 2'-OH. Previous biochemical data support the involvement of C629 and A701 in catalysis (Rastogi et al. 1996; Beattie and Collins 1997; Sood et al. 2002; Jones and Strobel 2003). Mutation of C629 by A, G, or $\mathrm{U}$ leads to more than a 10-fold loss in the activity of a self-cleaving ribozyme (Rastogi et al. 1996) and modification interference data support the importance of the C629 base (Beattie and Collins 1997). The importance of A701 $2^{\prime}-\mathrm{OH}$ was also revealed from studies that analyzed the contribution of $2^{\prime}-\mathrm{OH}$ to the cleavage and ligation activities (Sood et al. 2002; Jones and Strobel 2003). Overall, our current model of the SLI/SLV interaction is consistent with existing biochemical data and allows us to propose new interactions at the loop I/loop $\mathrm{V}$ interface.

To more thoroughly address the role of U700, we removed residue U700 from our models and subjected them to energy minimization. We obtained structural models of the SLI/DU700SLV complex (data not shown) that are fully compatible with all the restraints used for minimization of the SLI/SLV complex, including all NMR restraints previously used for structure calculation of $\mathrm{SLV}^{\mathrm{Mg}}$ (except those involving U700) (Campbell et al. 2006). In the SLI/DU700SLV model, the three loop/loop WatsonCrick base pairs were maintained, as well as the position of C629 with respect to SLV, indicating that deletion of U700 is compatible with our three-dimensional model of the SLI/SLV interaction. This result is not surprising, given that both the base and the ribose of U700 are completely extruded from the U-turn loop structure of $\mathrm{SLV}^{\mathrm{Mg}}$ (Fig. 2).

\section{DISCUSSION}

Substrate recognition by the VS ribozyme involves an important and well-characterized $\mathrm{Mg}^{2+}$-dependent loop/ loop interaction between the SLI substrate and SLV from the catalytic domain. In the 5-nt loop of SLV, the sequence requirement and the role(s) of the first four nucleotides have been clearly defined; U696, G697, and A698 form a UNR sequence necessary for U-turn formation and G697, A698, and C699 form Watson-Crick base pairs with SLI residues C632, U631, and G630, respectively (Rastogi et al. 1996). The roles of the fifth nucleotide, U700, and of the loop-closing base pair have not been clearly established, and the possibility for nucleotide insertion in the SLV loop has not been previously examined. Given the fact that U700 undergoes the largest conformational change between the NMR structures of SLV free and $\mathrm{SLV}^{\mathrm{Mg}}$, and that $\mathrm{Mg}^{2+}$ ions 
stabilize the loop I/loop V interaction, we were particularly intrigued by the role of U700 in this interaction.

\section{Formation of a canonical U-turn structure in SLV is neither necessary nor sufficient for SLI recognition}

From previous NMR studies, we observed that the loop of SLV undergoes a conformational change from a loose noncanonical U-turn to a compact canonical U-turn structure in the presence of magnesium ions. Here, we developed an NMR-based assay specifically designed to structurally characterize U-turn formation in SLV mutants. From our study, we could not establish a correlation between the formation of a canonical U-turn structure and the $\mathrm{k}_{\mathrm{cat}} / \mathrm{K}_{\mathrm{M}}$ values of the mutants. We observed that mutants with an activity similar to wild-type $\left[\left(\mathrm{k}_{\mathrm{cat}} / \mathrm{K}_{\mathrm{M}}\right)_{\mathrm{WT}} /\left(\mathrm{k}_{\mathrm{cat}} / \mathrm{K}_{\mathrm{M}}\right)_{\mathrm{MUT}} \leq\right.$ 4], U700C, and $+\mathrm{U} \wedge \mathrm{U} 700$ for example, did not adopt a compact canonical U-turn structure like the wild-type RNA. These mutants likely adopt a loose noncanonical U-turn structure that allows the correct positioning of the G697, A698, and C699 bases for pairing with loop I, but the details of these SLV loop structures are not available. Conversely, the U695G/DU700 mutant adopts a canonical U-turn structure, but its $\mathrm{k}_{\mathrm{cat}} / \mathrm{K}_{\mathrm{M}}$ is significantly reduced compared with the wild-type ribozyme value. Thus, formation of a canonical U-turn structure is neither necessary nor sufficient to allow a favorable interaction with SLI.

\section{Many mutations in SLV are compatible with SLI recognition}

Most mutations in our study yield $\mathrm{k}_{\mathrm{cat}} / \mathrm{K}_{\mathrm{M}}$ values that are not significantly reduced when compared with the wildtype ribozyme $\left.\left[\left(\mathrm{k}_{\mathrm{cat}} / \mathrm{K}_{\mathrm{M}}\right)_{\mathrm{WT}} /\left(\mathrm{k}_{\mathrm{cat}} / \mathrm{K}_{\mathrm{M}}\right)_{\mathrm{MUT}} \leq 4\right)\right]$, indicating that these loop mutations are compatible with the proper folding and catalytic activity of the VS ribozyme. We concluded that these mutations did not significantly affect SLI substrate recognition.

Mutation of the loop-closing U695-A701 base pair by a C-G base pair had only a small effect on $k_{\text {cat }} / K_{M}$. These results are in agreement with previous self-cleavage studies in which the U695G/A701C mutant was found to be slightly more active that the wild-type ribozyme (Beattie et al. 1995). Different types of Watson-Crick base pairs are therefore compatible with SLI recognition. In addition, mutation of the loop-closing U695-A701 base pair by a G-A base pair had only a small effect on ribozyme activity, which indicates that noncanonical base pair(s) can also be compatible with SLI recognition.

Given the importance of U700 for SLI recognition, we were interested to see if insertions in loop $\mathrm{V}$ were compatible with catalysis. It appears that addition of an extra $\mathrm{U}$ residue $(+\mathrm{U} \wedge \mathrm{U} 700$ mutant $)$ caused a minor decrease in $\mathrm{k}_{\text {cat }} / \mathrm{K}_{\mathrm{M}}$; however, addition of a dinucleotide $(+\mathrm{UC} \wedge \mathrm{U} 700)$ had a more dramatic effect. The NMR data for both of these mutants did not provide any evidence of U-turn structure formation. Although a single loop insertion in SLV supports SLI binding, larger loop insertions, like that of $+\mathrm{UC}^{\wedge} \mathrm{U} 700$, could favor loop conformations that are not compatible with SLI recognition.

Substitutions of U700 by A, C, and G were performed to investigate the role of the base at position 700 . The kinetic data indicate that these SLV mutants bind SLI similarly to the wild-type SLV, and, therefore, that the U700 base plays a negligible role in SLI recognition. These results are in agreement with modification interference experiments, in which the U700 base was removed without significantly affecting the self-cleavage activity of the VS ribozyme (Beattie and Collins 1997). In summary, we found that SLI recognition is compatible with many different loopclosing base pairs in SLV, a single nucleotide insertion in the SLV loop, and any of the four common bases at U700.

\section{Deletion of U700 is likely detrimental to $\mathrm{SLI}$ recognition}

Although base mutations of U700 have negligible effects on ribozyme activity, deletion of U700 substantially reduces $\mathrm{k}_{\mathrm{cat}} / \mathrm{K}_{\mathrm{M}}$. The reduction of $\mathrm{k}_{\mathrm{cat}} / \mathrm{K}_{\mathrm{M}}$ for the $\Delta \mathrm{U} 700$ mutant is similar to that of the C699G mutant, which was expected to abrogate the loop I/loop V interaction (Rastogi et al. 1996). The NMR chemical-shift changes of $\Delta \mathrm{U} 700$ are similar to that of U700C, indicating the presence of a noncanonical U-turn fold for $\Delta \mathrm{U} 700$ and suggesting that the reduced activity of $\Delta \mathrm{U} 700$ is not due to a completely misfolded U-turn structure. Although we cannot eliminate the possibility that deletion of U700 affects other aspects of catalysis (e.g., the folding of the ribozyme and the rate of cleavage), it appears that deletion of U700 is detrimental to SLI recognition.

It is peculiar that U700 can be mutated by any other base, but cannot be deleted. This suggests a role for this nucleotide that does not involve interactions to the base. However, the backbone of U700 likely plays a role in substrate recognition. Our structural modeling of the SLI/ SLV interaction suggests that the ribose and $5^{\prime}$-phosphate of U700 are too remote to allow for a direct interaction with SLI. Our modeling studies of a SLI/DU700SLV complex also indicate that in silico deletion of U700 does not significantly affect the structure of the complex. The remaining roles for the U700 backbone include providing direct interactions with a magnesium ion and/or other parts of the ribozyme, acting as a spacer, and/or providing a dynamic element that imparts an entropic advantage to substrate binding.

The backbone of U700 could participate in direct interactions with magnesium ions or other parts of the ribozymes. Previous studies have indicated that a 2'-deoxy at U700 and phosphorothioate substitutions at U700 (for 
both the $5^{\prime}$-phosphate and the $3^{\prime}$-phosphate) do not significantly affect cleavage and ligation activities (Sood et al. 1998, 2002; Jones and Strobel 2003). In the phosphorothioate substitution experiments, the VS ribozyme was transcribed by T7 RNA polymerase, which produces only the Rp phosphorothiate isomer, but not the Sp isomer (Sood et al. 1998; Jones and Strobel 2003). It is therefore possible that the pro-Sp oxygens of the $5^{\prime}$ - and $3^{\prime}$ phosphates of U700 are involved in binding a metal, and this is consistent with the large conformational change in the backbone of U700 upon addition of magnesium ions (see Fig. 2; Campbell et al. 2006). Four $\mathrm{Mg}^{2+}$-binding sites were recently identified in the SLV loop structure (Fig. 2) from paramagnetic NMR studies; one of them involves the pro-Sp oxygen of the 5'-phosphate of U700 (Campbell et al. 2006). Interaction of a magnesium ion with the backbone of U700 may therefore be important for stabilizing the loop I/loop $\mathrm{V}$ interaction and/or mediating interactions of the SLI/SLV junction with other parts of the ribozyme (Hiley et al. 2002).

As a spacer, the backbone of U700 could provide sufficient flexibility in the SLV loop to allow an optimal loop I/loop V interaction and proper docking of SLI at the active site. By increasing the SLV loop dynamics, the backbone of U700 could also provide an entropic advantage for SLI recognition. Studies of protein/ligand interactions indicate that biomolecular associations often involve dynamic residues that can provide a favorable entropic contribution to binding (Homans 2005). Further studies are required to determine whether a similar entropic contribution is important for SLI recognition by the VS ribozyme and for RNA/RNA interactions in general.

\section{Conclusion}

Interpretation of structure-function studies of macromolecules is often complicated by the fact that it is difficult to obtain structural data on the mutants being functionally characterized. In this study, kinetic characterization of loop $\mathrm{V}$ mutants of the VS ribozyme was complemented by a convenient NMR-based assay specifically designed to structurally characterize U-turn formation in these SLV mutants. In addition, homology modeling of the SLI/SLV interaction with MC-Sym generated a three-dimensional model that is in agreement with previous biochemical data. The MC-Sym model was useful for the interpretation of our kinetic data and allowed us to propose novel interactions at the loop I/loop $\mathrm{V}$ interface that are supported from previous biochemical studies.

From a comparative analysis of the kinetic and NMR data, we conclude that formation of a canonical U-turn structure in SLV is neither necessary nor sufficient for SLI recognition. Our kinetic studies reveal that many SLV mutations are compatible with the VS ribozyme activity, including substitutions of the loop-closing base pair, a single nucleotide insertion, and U700 base substitutions. However, deletion of the extruded loop residue U700 significantly impairs the ribozyme activity. The reduced activity of the U700 deletion mutants is neither due to a completely misfolded U-turn structure in SLV nor to interactions involving the U700 base. Rather, the backbone of U700 likely plays a role in SLI substrate recognition. The backbone of U700 may provide a direct interaction with a magnesium ion and/or other parts of the ribozyme that contribute to SLI recognition. Alternatively, the backbone of U700 could act as a spacer that allows loop V to optimally recognize the SLI substrate and/or provide a dynamic element that imparts an entropic advantage to substrate binding. NMR structure determination and relaxation studies of an SLI/SLV complex are now in progress in our laboratory to gain a better structural understanding of the loop I/loop $\mathrm{V}$ interaction and provide insight into the role that entropy plays in this interaction.

\section{MATERIALS AND METHODS}

\section{Plasmids}

The plasmid A-3, which allows for production of the AvaI ribozyme (Rz), has been described (Guo and Collins 1995). The stem-loop V mutants (Fig. 3) of Rz were prepared by using the QuickChangeII site-directed mutagenesis method (Stratagene). All plasmids created for this study were validated by DNA sequencing.

\section{Preparation of RNA for kinetic studies}

For kinetic studies of trans cleavage, the AvaI ribozyme (Rz) and the SLI(T) substrate $(\mathrm{S})$ were used. Rz contains a nine-nucleotide leader ( $5^{\prime}$-gggaaagcu) followed by the VS nucleotides 640-783 (Fig. 1). The wild-type and mutant sequences of Rz (Fig. 3) were prepared by in vitro T7 RNA polymerase transcription from plasmid A-3 (Guo and Collins 1995) linearized at the SspI site. All RNAs were purified by electrophoresis in $5 \%(\mathrm{w} / \mathrm{v})$ polyacrylamide gels containing $7 \mathrm{M}$ urea. They were visualized by UV shadowing, eluted from the selected gel slices by crush and soak at $42^{\circ} \mathrm{C}$, ethanol precipitated, and resuspended in water. The RNAs were applied to a semipreparative DNAPac PA100 column (Dionex) heated at $65^{\circ} \mathrm{C}$ (Shields et al. 1999) and equilibrated with buffer A ( $25 \mathrm{mM}$ Tris at $\mathrm{pH} 7.6$ and $2 \mathrm{mM}$ EDTA). They were eluted from the HPLC column using a gradient of buffer B (25 mM Tris at $\mathrm{pH} 7.6,2 \mathrm{mM}$ EDTA and $2 \mathrm{M} \mathrm{NaCl}$ ). The eluted RNAs were collected on ice, pooled, concentrated with a Centricon3 ultrafiltration device (Millipore), and exchanged into storage buffer (10 mM Tris at pH 7.5 and $1 \mathrm{mM}$ EDTA).

The $\operatorname{SLI}(\mathrm{T})$ RNA is a preshifted substrate with the sequence: 5'-GAGCGAAGGGCAUCGUCGGCCCGAGCUC-3'. It was synthesized in vitro using T7 RNA polymerase and a single-stranded synthetic oligonucleotide template (Integrated DNA Technologies). SLI(T) was purified to single-nucleotide resolution by $20 \%$ denaturing gel electrophoresis, dephosphorylated at its $5^{\prime}$-end with calf alkaline phosphatase (Roche Molecular Biochemicals), and further purified by DEAE-Sephacel chromatography 
(Amersham Biosciences). The eluted RNA was concentrated with a Centricon-3 ultrafiltration device (Millipore) and exchanged into $10 \mathrm{mM} \mathrm{d}_{11}$-Tris ( $\mathrm{pH} 7.0$ ), $50 \mathrm{mM} \mathrm{NaCl}$, and $0.05 \mathrm{mM} \mathrm{NaN}_{3}$. The SLI(T) RNA was then $5^{\prime}$-end-labeled with $\gamma-\left({ }^{32} \mathrm{P}\right)$ ATP (PerkinElmer LAS Canada Inc.) using T4 polynucleotide kinase (New England Biolabs) according to the manufacturer's instructions and further purified by $20 \%$ denaturing gel electrophoresis. After gel extraction, the ${ }^{32} \mathrm{P}$-labeled SLI(T) RNA was resuspended in TE (10 mM Tris at pH 7.6 and $1 \mathrm{mM}$ EDTA) and desalted over a Micro Bio-Spin 6 chromatography column (Bio-Rad).

\section{Kinetic studies}

All reactions were carried out at $30^{\circ} \mathrm{C}$ in reaction buffer $(50 \mathrm{mM}$ Tris at $\mathrm{pH} 7.5,25 \mathrm{mM} \mathrm{KCl}, 2 \mathrm{mM}$ spermidine and $25 \mathrm{mM}$ $\mathrm{MgCl}_{2}$ ). Prior to the cleavage reaction, the ${ }^{32} \mathrm{P}$-labeled SLI(T) substrate was heated to $95^{\circ} \mathrm{C}$ for $1 \mathrm{~min}$ in storage buffer and snapcooled in iced water to promote hairpin formation. Cleavage reactions were initiated by addition of an equal volume $(20 \mu \mathrm{L})$ of the ${ }^{32} \mathrm{P}$-labeled SLI(T) substrate $(\mathrm{S})$ and the AvaI ribozyme $(\mathrm{Rz})$, either the wild-type (WT) or SLV loop mutants (Fig. 3), after a 5 -min preincubation of $\mathrm{S}$ and $\mathrm{Rz}$ at $30^{\circ} \mathrm{C}$ in reaction buffer. Typically, about 10 aliquots of $3 \mu \mathrm{L}$ were removed from the $40-\mu \mathrm{L}$ reaction mixture at specific times, and the reaction was stopped by addition of $12 \mu \mathrm{L}$ of stop mix (50 mM EDTA at $\mathrm{pH} 8.0,0.04 \%$ xylene cyanol, $0.04 \%$ bromophenol blue, and $\geq 85 \%$ formamide) and transfer to $4^{\circ} \mathrm{C}$. Reaction products were separated by electrophoresis on $20 \%$ polyacrylamide/7 M urea gels. For each time point, the amount of substrate and product were quantified using the Molecular Imager FX and the Quantity One 1D analysis software version 4.6.2 from Bio-Rad Laboratories.

Single-turnover kinetic experiments were typically performed with $[\mathrm{S}]=0.25 \mathrm{nM}$ and excess Rz. Reactions were first order for approximately three half-lives and end points were $90 \%-99 \%$. The extent of the reaction was calculated as $\left(\mathrm{S}_{t}^{*}\right) /\left(\mathrm{S}_{\mathrm{t}=0}{ }^{*}\right)$, where $\mathrm{S}_{t}^{*}=$ $\mathrm{S}_{t}-\mathrm{S}_{t \rightarrow \infty} ; \mathrm{S}_{\mathrm{t}=0}^{*}=\mathrm{S}_{\mathrm{t}=0}-\mathrm{S}_{t \rightarrow \infty} ; \mathrm{S}_{t}$ is the amount of $\mathrm{S}$ at time $t$; $S_{t \rightarrow \infty}$ is the amount of $S$ at the end point; and $S_{t=0}$ is the initial amount of $\mathrm{S}$. The natural $\log$ of $\left(\mathrm{S}_{t}^{*}\right) /\left(\mathrm{S}_{\mathrm{t}=0^{*}}\right)$ was plotted against the time of the reaction, and the value of $\mathrm{k}_{\mathrm{obs}}$ was obtained from the slope by linear regression. The linear dependence of $\mathrm{k}_{\mathrm{obs}}$ on $[\mathrm{Rz}]$ was also analyzed by linear regression to derive the secondorder rate constant of the reaction, $\mathrm{k}_{\mathrm{cat}} / \mathrm{K}_{\mathrm{M}}$. The linear dependence of $\mathrm{k}_{\mathrm{obs}}$ on $[\mathrm{Rz}]$ was observed from $5 \mathrm{nM}$ to $500 \mathrm{nM}$ for the wild-type and U700G Rz, from $50 \mathrm{nM}$ to $3 \mu \mathrm{M}$ for U700A, U700C, U695C/A701G, U695G, and $+\mathrm{U} \wedge \mathrm{U} 700 \mathrm{Rz}$, and from $50 \mathrm{nM}$ to $5 \mu \mathrm{M}$ for all other mutant Rz. Kinetic experiments were all performed at least three times, and reported $\mathrm{k}_{\mathrm{cat}} / \mathrm{K}_{\mathrm{M}}$ and their errors are average values and standard deviations, respectively, from these multiple measurements.

\section{Preparation of ${ }^{15} \mathrm{~N}$-labeled SLV RNA fragments for native gel and NMR studies}

A total of 10 SLV RNA fragments were chosen for NMR analysis, one containing the wild-type loop sequence (Fig. 4A) and nine others derived from this RNA, but containing selected loop mutations (Fig. 3). These SLV RNA fragments were synthesized in vitro using T7 RNA polymerase, a single-stranded DNA template, and ${ }^{15} \mathrm{~N}$-labeled NTPs, and they were purified as previously described (Campbell and Legault 2005). The final concentration of the ${ }^{15} \mathrm{~N}$-labeled SLV RNA samples for NMR studies ranged from 0.8 to $1.2 \mathrm{mM}$. The sample buffer was exchanged by use of Centricon-3 ultrafiltration devices with either NMR buffer A (10 $\mathrm{mM} \mathrm{d}_{11}$-Tris at $\mathrm{pH} 7.0,50 \mathrm{mM} \mathrm{NaCl}$, and $0.05 \mathrm{mM} \mathrm{NaN}_{3}$ ), NMR buffer B (10 $\mathrm{mM} \mathrm{d}_{11}$-Tris at $\mathrm{pH} 7.0$ and $\left.0.05 \mathrm{mM} \mathrm{NaN}_{3}\right)$, or NMR buffer $\mathrm{C}\left(10 \mathrm{mM} \mathrm{d}_{11}\right.$-Tris at $\mathrm{pH} 7.0,20 \mathrm{mM} \mathrm{MgCl}_{2}$, and $0.05 \mathrm{mM} \mathrm{NaN}_{3}$ ), which contained $90 \% \mathrm{H}_{2} \mathrm{O}$ and $10 \% \mathrm{D}_{2} \mathrm{O}$. For studies in $\mathrm{D}_{2} \mathrm{O}$, the RNA samples were transferred to $99.996 \%$ $\mathrm{D}_{2} \mathrm{O}$ with multiple cycles of lyophilisation and resuspension in $\mathrm{D}_{2} \mathrm{O}$. Before exchanging in NMR buffer $\mathrm{C}$, the RNA samples were exchanged in NMR buffer A or NMR buffer B and heated to $95^{\circ} \mathrm{C}$ for $2 \mathrm{~min}$ and then immediately cooled in iced water.

\section{Native gel studies of SLV fragments}

Nondenaturing polyacrylamide gel electrophoresis was carried out on $7.5 \%$ polyacrylamide gels, acrylamide: bis (37.5: 1) in TB buffer (50 mM Tris borate at $\mathrm{pH} 8.0$ and $20 \mathrm{mM}$ magnesium acetate). The gels were prerun for $30 \mathrm{~min}$ at $200 \mathrm{~V}$, loaded with the SLV RNA fragments $(2 \mu \mathrm{g}$ RNA at a concentration of $20 \mu \mathrm{M})$ and then run for $2 \mathrm{~h}$ at $250 \mathrm{~V}$ and $4^{\circ} \mathrm{C}$. The gels were stained with Stains All (Sigma-Aldrich).

\section{NMR studies of SLV fragments}

All NMR experiments were conducted at $25^{\circ} \mathrm{C}$ on a Varian

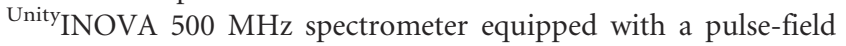
gradient unit and an actively shielded $\mathrm{z}$ gradient probe, either a ${ }^{1} \mathrm{H}\left\{{ }^{13} \mathrm{C} /{ }^{15} \mathrm{~N}\right\}$ triple resonance probe or a ${ }^{1} \mathrm{H}\left\{{ }^{15} \mathrm{~N}-{ }^{31} \mathrm{P}\right\}$ indirect detection probe. The following experiments were recorded: a $1 \mathrm{D}$ ${ }^{15} \mathrm{~N}$-decoupled ${ }^{1} \mathrm{H}$ flip-back watergate spectrum (in $\mathrm{H}_{2} \mathrm{O}$ ); a $1 \mathrm{D}$ ${ }^{1} \mathrm{H}$-decoupled ${ }^{31} \mathrm{P}$ spectrum (in $\mathrm{H}_{2} \mathrm{O}$ ); and a long-range $2 \mathrm{D}{ }^{1} \mathrm{H}$ ${ }^{15} \mathrm{~N}$ HMQC spectrum (Kay and Bax 1990) optimized for detection of adenine $\mathrm{N} 1$ and $\mathrm{N} 3$ and purine $\mathrm{N} 7$ and $\mathrm{N} 9$ (in $\mathrm{D}_{2} \mathrm{O}, J=21 \mathrm{~Hz}$ ). The 2D spectra were processed and analyzed with the NMRPipe/ NMRDraw package (Delaglio et al. 1995). ${ }^{1} \mathrm{H}$ and ${ }^{15} \mathrm{~N}$ chemical shifts were referenced to an external standard of 2,2-dimethyl2-silapentane-5-sulfonic acid (DSS) at $0.00 \mathrm{ppm}$ (Wishart et al. 1995) and ${ }^{31} \mathrm{P}$ chemical shifts were referenced to an external standard of $85 \%$ phosphoric acid at $0.00 \mathrm{ppm}$.

\section{Homology modeling of the SLI/SLV interaction}

Three-dimensional models of the SLI / SLV interaction were built using MC-Sym version 4.2.0 (Major et al. 1991; Major 2003). The modeling strategy was to generate ensembles of structures for both SLI and SLV hairpins, and merge all combinations of the SLI and SLV structures via the formation of Watson-Crick base pairing interactions for G630-C699, U631-A698, and C632-G697. For the ensemble of SLV structures, we used the 11 structural coordinates of SLV ${ }^{\mathrm{Mg}}$ from PDB entry 1YN1 (Campbell et al. 2006). For the ensemble of SLI structures (wild-type residues 623-637), we generated structures that satisfied a number of base relations and inter-atomic distance restraints in order to obtain an A-form helix for the stem (Watson-Crick base pairing for 623-637, 624636, 625-635, and 626-633) with an extra helical C634 residue and a U-turn structure in the loop with stacking of C629, G630, U631, and C632. A total of seven models of the SLI/SLV complex were obtained that fit the input restraints and that were structurally distinct from each other (heavy atom RMSD between 2.4 and 
$3.1 \AA$ ). These models were energy minimized using X-PLOR-NIH version 2.0.6 (Schwieters et al. 2003). For the energy minimization, the force field consisted of bond, angle, improper (stereochemistry), and repulsive van der Waals energy terms. In addition, distance and torsion angle pseudo-energy terms were used to maintain the structural integrity of the complex. All NMR-derived distance restraints used for determination of the $\mathrm{SLV}^{\mathrm{Mg}}$ structure (Campbell et al. 2006) were included along with restraints to enforce A-form geometry in the stem of SLI, a U-turn structure in the SLI loop and Watson-Crick base-pairing at the loop I/loop V junction.

\section{ACKNOWLEDGMENTS}

We thank Richard A. Collins for providing plasmid A-3 and Ryan Richter for computer support. We also thank Richard A. Collins and James G. Omichinski for critical reading of the manuscript. This work was supported by a grant from the Canadian Institutes for Health Research (CIHR \#117713). J.L.-L. holds a Ph.D. scholarship from the Université de Montréal. P.B. holds Ph.D. scholarships from CIHR and the Université de Montréal. G.D. holds scholarships from the Fonds de la Recherche en Nature et Technologies (FQRNT) and from the Luigi-Liberatore Foundation. P.L. (the eighth author) holds a Canada Research Chair in Structural Biology of RNA.

Received September 13, 2007; accepted December 20, 2007.

\section{REFERENCES}

Andersen, A. and Collins, R.A. 2000. Rearrangement of a stable RNA secondary structure during VS ribozyme catalysis. Mol. Cell 5: $469-478$

Andersen, A.A. and Collins, R.A. 2001. Intramolecular secondary structure rearrangement by the kissing interaction of the Neurospora VS ribozyme. Proc. Natl. Acad. Sci. 98: 7730-7735.

Beattie, T.L. and Collins, R.A. 1997. Identification of functional domains in the self-cleaving Neurospora VS ribozyme using damage selection. J. Mol. Biol. 267: 830-840.

Beattie, T.L., Olive, J.E., and Collins, R.A. 1995. A secondary-structure model for the self-cleaving region of Neurospora VS RNA. Proc. Natl. Acad. Sci. 92: 4686-4690.

Cabello-Villegas, J., Tworowska, I., and Nikonowicz, E.P. 2004. Metal ion stabilization of the U-turn of the $\mathrm{A}_{37} \mathrm{~N}^{6}$-dimethylallylmodified anticodon stem-loop of Escherichia coli tRNA ${ }^{\text {Phe }}$. Biochemistry 43: 55-66.

Campbell, D.O. and Legault, P. 2005. NMR structure of the Varkud satellite ribozyme stem-loop V RNA and magnesiumion binding from chemical-shift mapping. Biochemistry 44: 41574170 .

Campbell, D.O., Bouchard, P., Desjardins, G., and Legault, P. 2006. NMR structure of Varkud satellite ribozyme stem-loop V in the presence of magnesium ions and localization of metal-binding sites. Biochemistry 45: 10591-10605.

Collins, R.A. 2002. The Neurospora Varkud satellite ribozyme. Biochem. Soc. Trans. 30: 1122-1126.

Delaglio, F., Grzesiek, S., Vuister, G.W., Zhu, G., Pfeifer, J., and Bax, A. 1995. NMRPipe: A multidimensional spectral processing system based on UNIX pipes. J. Biomol. NMR 6: 277-293.

Fersht, A.R., Shi, J.P., Knill-Jones, J., Lowe, D.M., Wilkinson, A.J., Blow, D.M., Brick, P., Carter, P., Waye, M.M., and Winter, G. 1985. Hydrogen bonding and biological specificity analyzed by protein engineering. Nature 314: 235-238.
Fire, A., Xu, S., Montgomery, M.K., Kostas, S.A., Driver, S.E., and Mello, C.C. 1998. Potent and specific genetic interference by double-stranded RNA in Caenorhabditis elegans. Nature 391: 806-811.

Flinders, J. and Dieckmann, T. 2001. A pH controlled conformational switch in the cleavage site of the VS ribozyme substrate RNA. J. Mol. Biol. 308: 665-679.

Flinders, J. and Dieckmann, T. 2004. The solution structure of the VS ribozyme active site loop reveals a dynamic "hot-spot.". J. Mol. Biol. 341: 935-949.

Guo, H.C.T. and Collins, R.A. 1995. Efficient trans-cleavage of a stem-loop RNA substrate by a ribozyme derived from Neurospora VS RNA. EMBO J. 14: 368-376.

Herschlag, D. and Cech, T.R. 1990. Catalysis of RNA cleavage by the Tetrahymena thermophila ribozyme. 1. Kinetic description of the reaction of an RNA substrate complementary to the active site. Biochemistry 29: 10159-10171.

Hiley, S.L. and Collins, R.A. 2001. Rapid formation of a solventinaccessible core in the Neurospora Varkud satellite ribozyme. EMBO J. 20: 5461-5469.

Hiley, S.L., Sood, V.D., Fan, J., and Collins, R.A. 2002. 4-thio-U crosslinking identifies the active site of the VS ribozyme. EMBO J. 21: 4691-4698.

Hoffmann, B., Mitchell, G.T., Gendron, P., Major, F., Andersen, A.A., Collins, R.A., and Legault, P. 2003. NMR structure of the active conformation of the Varkud satellite ribozyme cleavage site. Proc. Natl. Acad. Sci. 100: 7003-7008.

Homans, S.W. 2005. Probing the binding entropy of ligand-protein interactions by NMR. ChemBioChem 6: 1585-1591.

Jones, F.D. and Strobel, S.A. 2003. Ionization of a critical adenosine residue in the Neurospora Varkud satellite ribozyme active site. Biochemistry 42: 4265-4276.

Kay, L.E. and Bax, A. 1990. New methods for the measurement of $\mathrm{NH}-\mathrm{C} \alpha \mathrm{H}$ coupling constants in ${ }^{15} \mathrm{~N}$-labeled proteins. J. Magn. Reson. 86: 110-126.

Kraut, D.A., Carroll, K.S., and Herschlag, D. 2003. Challenges in enzyme mechanism and energetics. Annu. Rev. Biochem. 72: 517-571.

Lafontaine, D.A., Wilson, T.J., Norman, D.G., and Lilley, D.M. 2001. The A730 loop is an important component of the active site of the VS ribozyme. J. Mol. Biol. 312: 663-674.

Lafontaine, D.A., Norman, D.G., and Lilley, D.M. 2002. The global structure of the VS ribozyme. EMBO J. 21: 2461-2471.

Lilley, D.M. 2004. The Varkud satellite ribozyme. RNA 10: 151-158.

Major, F. 2003. Building three-dimensional ribonucleic acid structures. Comput. Sci. Eng. 5: 44-53.

Major, F., Turcotte, M., Gautheret, D., Lapalme, G., Fillion, E., and Cedergren, R. 1991. The combination of symbolic and numerical computation for three-dimensional modeling of RNA. Science 253: 1255-1260.

Michiels, P.J.A., Schouten, C.H.J., Hilbers, C.W., and Heus, H.A. 2000. Structure of the ribozyme substrate hairpin of Neurospora VS RNA: A close look at the cleavage site. RNA 6: 1821-1832.

Rastogi, T., Beattie, T.L., Olive, J.E., and Collins, R.A. 1996. A longrange pseudoknot is required for activity of the Neurospora VS ribozyme. $E M B O$ J. 15: 2820-2825.

Saville, B.J. and Collins, R.A. 1990. A site-specific self-cleavage reaction performed by a novel RNA in Neurospora mitochondria. Cell 61: 685-696.

Saville, B.L. and Collins, R.A. 1991. RNA-mediated ligation of selfcleavage products of a Neurospora mitochondrial plasmid transcript. Proc. Natl. Acad. Sci. 88: 8826-8830.

Schweisguth, D.C. and Moore, P.B. 1997. On the conformation of the anticodon loops of initiator and elongator methionine tRNAs. J. Mol. Biol. 267: 505-519.

Schwieters, C.D., Kuszewski, J.J., Tjandra, N., and Clore, G.M. 2003. The Xplor-NIH NMR molecular structure determination package. J. Magn. Reson. 160: 66-74.

Shields, T.P., Mollova, E., Ste Marie, L., Hansen, M.R., and Pardi, A. 1999. High-performance liquid chromatography purification of 


\section{Bouchard et al.}

homogenous-length RNA produced by trans cleavage with a hammerhead ribozyme. RNA 5: 1259-1267.

Sood, V.D., Beattie, T.L., and Collins, R.A. 1998. Identification of phosphate groups involved in metal binding and tertiary interactions in the core of the Neurospora VS ribozyme. J. Mol. Biol. 282: 741-750.

Sood, V.D., Yekta, S., and Collins, R.A. 2002. The contribution of 2'hydroxyls to the cleavage activity of the Neurospora VS ribozyme. Nucleic Acids Res. 30: 1132-1138. doi: 10.1093/nar/30.5.1132.

Sundaram, M., Durant, P.C., and Davis, D.R. 2000. Hypermodified nucleosides in the anticodon of tRNA ${ }^{\text {Lys }}$ stabilize a canonical Uturn structure. Biochemistry 39: 12575-12584.

Svoboda, P. and Di Cara, A. 2006. Hairpin RNA: A secondary structure of primary importance. Cell. Mol. Life Sci. 63: 901-908.
Wilkinson, A.J., Fersht, A.R., Blow, D.M., and Winter, G. 1983. Sitedirected mutagenesis as a probe of enzyme structure and catalysis: Tyrosyl-tRNA synthetase cysteine- 35 to glycine- 35 mutation. Biochemistry 22: 3581-3586.

Wilson, T.J., McLeod, A.C., and Lilley, D.M. 2007. A guanine nucleobase important for catalysis by the VS ribozyme. EMBO J. 26: $2489-2500$.

Wishart, D.S., Bigam, C.G., Yao, J., Dyson, H.J., Oldfield, E., Markley, J.L., and Sykes, B.D. $1995 .{ }^{1} \mathrm{H},{ }^{13} \mathrm{C},{ }^{15} \mathrm{~N}$ chemical shift referencing in biomolecular NMR. J. Biomol. NMR 6: 135140.

Zamel, R. and Collins, R.A. 2002. Rearrangement of substrate secondary structure facilitates binding to the Neurospora VS ribozyme. J. Mol. Biol. 324: 903-915. 

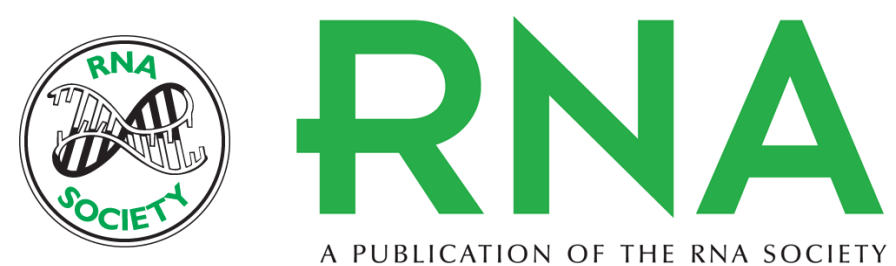

A PUBLICATION OF THE RNA SOCIETY

\section{Role of SLV in SLI substrate recognition by the Neurospora VS ribozyme}

Patricia Bouchard, Julie Lacroix-Labonté, Geneviève Desjardins, et al.

RNA 2008 14: 736-748

References This article cites 42 articles, 9 of which can be accessed free at: http://rnajournal.cshlp.org/content/14/4/736.full.html\#ref-list-1

\section{License}

Email Alerting Receive free email alerts when new articles cite this article - sign up in the box at the Service top right corner of the article or click here.

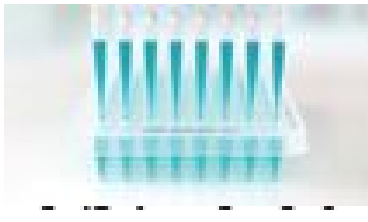

